\title{
Sustainability, Optimality, and Development Policy
}

\author{
Y. Hossein Farzin \\ Department of Agricultural and Resource Economics \\ University of California, Davis, CA 95616, U.S.A. \\ Farzin@primal.ucdavis.edu
}

\begin{abstract}
Considering sustainability a matter of intergenerational welfare equity, this paper examines whether an optimal development path can also be sustainable. It argues that the general "zero-net-aggregateinvestment" condition for an optimal development path to be sustainable in the sense of the maximin criterion of intergenerational justice is too demanding to be practical, especially in the context of developing countries. It further argues that while the maximin criterion of sustainability may be appealing to the rich advanced industrial countries, for the poor developing countries it implies equalization of poverty across generations, and as such is too costly a moral obligation to be acceptable. The paper suggests that a compromise development policy that follows the optimal growth approach but adopts certain measures to mitigate both the intergenerational and intragenerational welfare inequalities may be more appropriate for these countries. Some of the principal elements of such a policy are highlighted.
\end{abstract}

Key Words: Sustainability, intergenerational equity, optimality, discounting, development policy

JEL Codes: Q01, Q56, O21, O13, D62, D63

Previous versions of this paper were presented as invited lectures at the PGPPE 2009 Workshop on Public Policy, Externalities, and Growth, University of Graz, Austria, July 9-11, 2009 and at the International Symposium on Integrating Global Environmental Studies Towards Human Security, 22-23 June 2007, Kyoto University, Japan. For helpful comments, I thank T. Takebe, Phil Martin, Richard Sturn, Kazuo Nishimura, Kazuhiro Ueta, Ron Wendner and the participants at those forums and seminars at the Institute of Economic Research and the Graduate School of Environmental Studies, Kyoto University, Colorado State University at Fort Collins, University of Alberta, Canada, and UC Davis. However, I alone am responsible for any error of commission or omission. 


\section{Sustainability, Optimality, and Development Policy}

\section{Introduction}

"Sustainability" has come into vogue, but remains a vague concept, making it hard to test sustainability in practice. Many economists define sustainability as was done in the report of the World Commission on Environment and Development (WCED, 1987), the Bruntland Report. ${ }^{1}$ It defines sustainable economic development as: "development that meets the needs of present generation without compromising the ability of future generations to meet their own needs". Implicit in this definition are the two basic concepts of intergenerational fairness and economic optimality. Sustainability is a question of intergenerational equity, asking about the fair or just distribution of productive capacity and welfare between the present and future generations. Economic optimality, on the other hand, is concerned with attaining the highest feasible level of social welfare over the long run. Considering sustainability as a question of intergenerational equity in economic welfare, I focus on two basic questions. First: Is there a conflict between sustainability and optimality? Or, phrased differently, Can an optimal economic development path also be sustainable? Second: Is the intergenerational justice, especially in its puritanical form of the Rawls' maximin criterion, an appropriate social-economic objective for the poor developing countries to adopt?

I begin in section 2.1 by reviewing the main insights from the theory of optimal economic growth (Ramsey, 1928) and its extension to cases where a natural exhaustible resource is essential to production (Dasgupta and Heal, 1974, and 1979). In section 2.2, I consider the extreme case of intergenerational justice as defined by Rawls' maximin criterion and discuss its implications for economic sustainability in a simple model with a single consumption good, a reproducible manmade capital, and a natural exhaustible resource (Solow, 1974 and Hartwick, 1977) and expand this in section 2.3 to a very general model which includes many consumption goods and services, many man-made capitals and environmental stocks, and the direct (non-autonomous) effect of time (Farzin, 2006). Section 3 highlights the main limitations and practical difficulties with the implementation of sustainability rule as implied by the maximin criterion of intergenerational justice, emphasizing the important roles of scale, externalities, information, markets and other institutions in the design of a sustainability policy. In section 4, I argue that while the maximin rule of sustainability may offer a sensible approach for the rich industrial countries which have already

\footnotetext{
${ }^{1}$ It is beyond the scope and purpose of this paper to survey, even summarily, the vast literature on various aspects of economic sustainability to which many authors have contributed. For a review of various definitions of sustainability see Pezzey (1989) and World Bank (1997). See also Farzin (2004) who uses two alternative definitions of sustainability to show that even a purely exhaustible resource economy is under certain conditions sustainable according to one of the sustainability definitions.
} 
achieved high living standards, it turns into a "poverty equalizer" policy for the poor developing nations which are poorly endowed with some of the man-made capital assets crucial to growth of income and welfare. I argue that a compromise policy that adopts the optimal growth approach but modifies it in several ways to reduce intragenerational and intergenerational inequality may offer a more practical and promising alternative for developing countries. I outline some of the main elements of such a policy. Concluding remarks are in Section 5.

\section{Theoretical Insights}

\subsection{Ramsey's Utilitarian Approach}

The search for an economic development path that is both optimal and sustainable occupied economists as far back as Frank Ramsey (1928). Ramsey sought an optimal path for the capital stock to converge to some positive level and remain permanently at that level (i.e., a steady-state level) regardless of the initial size of the capital stock. However, characterizing sustainability by the steady-state of the economy, as in Ramsey's optimal growth model, has the problem that sustainability, if achievable at all, is attained only after the economy has reached its steady state. As such, it has no regard for intergenerational distribution of savings burden and consumption (welfare) in the transition period to the steady state, which may be a very long period, indeed.

To make this point clear and to form a basis for subsequent arguments, let us briefly revisit Ramsey's optimal growth model.

Ramsey model is a utilitarian one in that the social planner adopts a utilitarian social welfare function and aims to solve the following problem:

$$
\begin{array}{ll}
\underset{\{c(t)\}_{0}^{\infty}}{\operatorname{Maximize}} & \int_{0}^{\infty} U(c(t)) e^{-\rho t} d t \\
\text { s.t. } & \dot{k}(t)=f(k(t))-c(t)-(n+\delta) k(t) \\
& k(0)=k_{0}>0, \text { given } \\
& 0 \leq c(t) \leq f(k(t))
\end{array}
$$

where $U(c(t))$ is an increasing, strictly concave utility function, $c(t)$ consumption per head, $k(t)$ capital stock per head, $f(k(t))$ production technology yielding output per head, $\rho>0$ (constant) the pure time discount rate, $\delta$ (constant) capital stock depreciation rate, and $n$ (constant) population growth rate.

As is familiar, the evolution of Ramsey's economy along an optimal path is characterized by the pair of differential equations: 


$$
\begin{aligned}
& \dot{k}(t)=f(k(t))-c(t)-(n+\delta) k(t) \\
& \dot{c}(t)=c(t)\left[f^{\prime}(k(t))-(\rho+n+\delta)\right] / \eta \\
& \text { where } \eta \equiv-\frac{c u^{\prime \prime}(c)}{u^{\prime}(c)}
\end{aligned}
$$

\subsubsection{Some Important Sustainability Insights from Ramsey Model}

\section{(a) No Discounting of Future Welfare}

Ramsey objected to the discounting of future utilities as "ethically indefensible", and believed that it "arises merely from the weakness of imagination". If we follow this moral principle, so that $\rho=0$, and for simplicity's sake assume constant population and no capital stock depreciation ( $n=\delta=0)$, then from (1.1) and (1.2) we have that

$$
\dot{k}(t)=f(k(t))-c(t)>0 \text { and } \dot{c}(t)=c(t) f^{\prime}(k(t)) / \eta>0
$$

That is, there exists no steady state: along the optimal development path capital stock and consumption per head, and hence welfare, rise over time right from the beginning without bound. So, each successive generation will be better off than its previous generation, with the present generation being the least well off of all generations. Thus, we have the rather ironic result that:

In a utilitarian society, following the moral principle of treating the welfare of all generations equally (i.e., applying no discount rate) could result in an optimal outcome which is intergenerationally highly inequitable.

\section{(b) Discounting of Future Welfare}

Koopmans (1967a)(1967b) was the first economist who questioned the reasonableness of the moral principle that requires the welfare of all generations to be equally treated in the social welfare function. He showed that such a principle would result in unacceptably large sacrifices to be made by the present generation in that it would impose an unacceptably high savings burden, leaving the present generation almost destitute. Arrow (1996) confirms this argument by way of a thought-experiment, showing that if the present generation is presented with a one-time only investment opportunity which provides a small constant income forever, then with no discounting, the optimal decision requires that the present generation to invest its entire income, i.e., it should have a savings rate equal to 1. Interestingly, Arrow shows that the Koopmans' basic argument neither depends on uncertainty about the return on investment (although that uncertainty reinforces the argument) nor essentially on the assumption of an infinite time horizon. In regards to the latter, Arrow notes that even if the time horizon of the investment is reduced from infinity to say 3000 years and the return to investment is assumed to be as low as $1 \%$, with no discounting of future 
returns, the optimality still dictates that the present generation should save and invest almost $90 \%$ of its income- too high a saving rate by any ethical standard (I shall return to this point later).

So, how would the discounting of future generations' welfare alter the above conclusion about the intergenerational inequality associated with the utilitarian approach? It is easy to verify from (1.1) and (1.2) that regardless of whether the population is constant or grows at a constant rate $n>0$, and regardless of whether capital stock depreciates at a constant rate $\delta>0$ or not at all, there exists a steady-state for the economy. It is characterized by $\dot{k}(t)=\dot{c}(t)=0$, where the constant consumption per head and capital per head are obtained as solutions to the pair of equations:

$$
\begin{aligned}
& f(\bar{k})-\bar{c}-(n+\delta) \bar{k}=0 \\
& f^{\prime}(\bar{k})-(\rho+n+\delta)=0
\end{aligned}
$$

Assuming $k_{0}<\bar{k}$, the optimal policy will involve a transition period during which the consumption and capital per head rise over time until the economy reaches the steady state. Thereafter, for ever the consumption per head and hence welfare remains constant for all subsequent generations (see Figure 1).

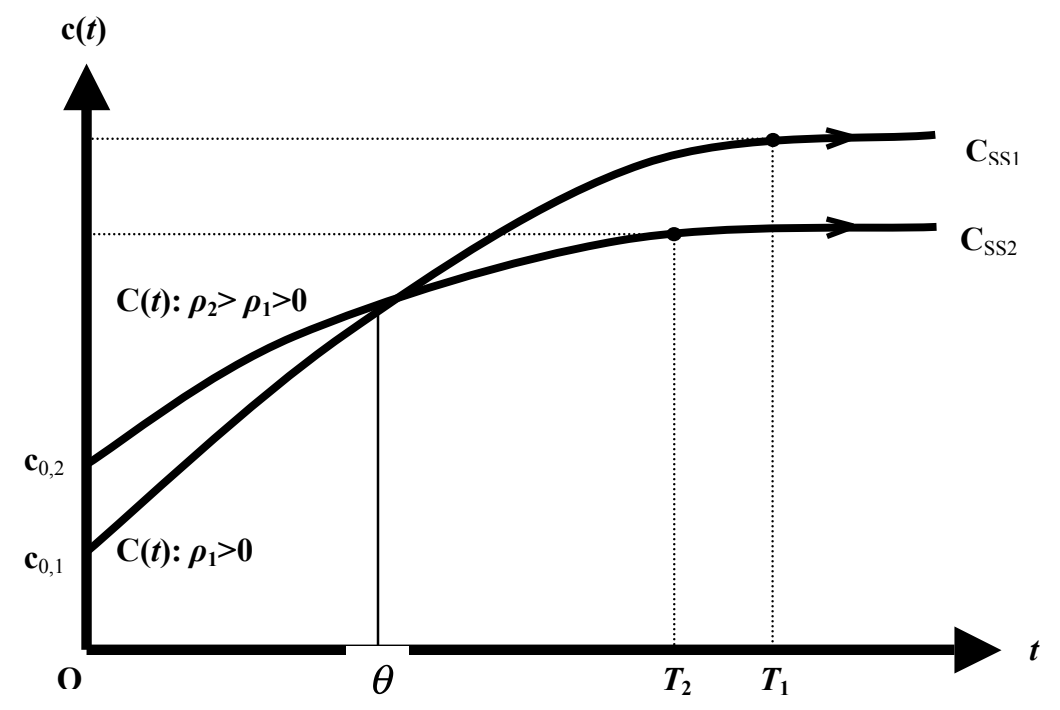

Figure 1: Optimal consumption path in Ramsey model

$\underline{\text { With discounting, } \rho>0}$

Thus, again, rather ironically, we have the following result: 
In the utilitarian model, although discounting of future welfare defies the moral principle of treating the welfare of all generations equally, it leads to an optimal outcome in which after certain initial period all future generations will enjoy an equal welfare level.

However, it is noted that for any positive discount rate $(\rho>0)$, the utilitarian economy still involves a transitional period during which intergenerational equality fails to prevail: during the transitional period earlier generations will be worse off than later generations who in turn will be less well off than those living in the steady state, with the present generation being the least well off of all. It is also noted that the higher the discount rate $\left(\rho_{2}>\rho_{1}\right.$ in Figure 1), the higher will be the consumption per head for some early generations $\left(c\left(t, \rho_{2}\right)>c\left(t, \rho_{1}\right)\right.$ for $\left.0 \leq \mathrm{t} \leq \theta\right)$, the shorter will be the transition period to the steady state $\left(T_{2}<T_{1}\right)$, and the lower will be the steady-state consumption per head $\left(\bar{c}\left(\rho_{2}\right)<\bar{c}\left(\rho_{1}\right)\right)^{2}$

Of course, given the historical context of the Ramsey model, the concept of capital stock in his model was limited to manufactured capital. As such, it ignored other types of capital stocks such as human capital, knowledge capital, social capital and in particular the important question of degradation and depletion of environmental and natural resource assets. This task was later undertaken by Solow (1974), Dasgupta and Heal (1974) (1979) and Stiglitz (1974) who generalized the Ramey model to include an exhaustible natural resource stock.

In a utilitarian framework, Dasgupta and Heal showed that with no discounting of the future generations' welfare $(\rho=0)$, and the assumptions of constant population, constant technology, and no capital depreciation, the inclusion of the exhaustible resource makes no difference to the conclusion reached in the Ramsey model: along the optimal path (when it exists) ${ }^{3}$, consumption, and hence utility, per head rises over time without bound and the exhaustible resource is used at rates that decline to zero as time approaches infinity. Thus, as in the Ramsey model with

\footnotetext{
${ }^{2}$ Not that in the limit when $\rho \rightarrow \infty, c(0) \rightarrow k_{0}$ and $c(t)=0$ for all $t>0$; that is, the optimal policy would involve the most extreme intergenerational inequality in that the present generation would consume up the initial capital endowment, thus forcing all subsequent generations to starve.

${ }^{3}$ With a Cobb-Douglas production function, $Q=F(K, R)=K^{\alpha} R^{\beta}, \alpha>\beta>0, \alpha+\beta<1$, where $K$ is the reproducible capital stock and $R$ is the input of an exhaustible resource, together with an iso-elastic utility function, $u(c)=c^{1-\eta} /(1-\eta), \eta>1$, the optimal policy exists if $\eta>(1-\beta) /(\alpha-\beta)$ (see Slow (1974) and Dasgupta and Heal (1979)).
} 
no natural resource stock, the optimal development path is at odds with intergenerational equality in consumption and welfare. ${ }^{4}$

Noteworthy in the utilitarian model is the role of the ethically based parameter $\eta$, which reflects the degree to which social preferences are egalitarian, or stating it differently, the degree of society's aversion to intergenerational welfare inequality. Not surprisingly, the larger is $\eta$ the flatter becomes the optimal path of consumption per head, implying a reduction in the degree of intergenerational inequality relative to a constant consumption path. In fact, in the extreme case when $\eta \rightarrow \infty$ the optimal path of consumption per head becomes a constant path, implying intergenerational equality in consumption (see Figure 2).

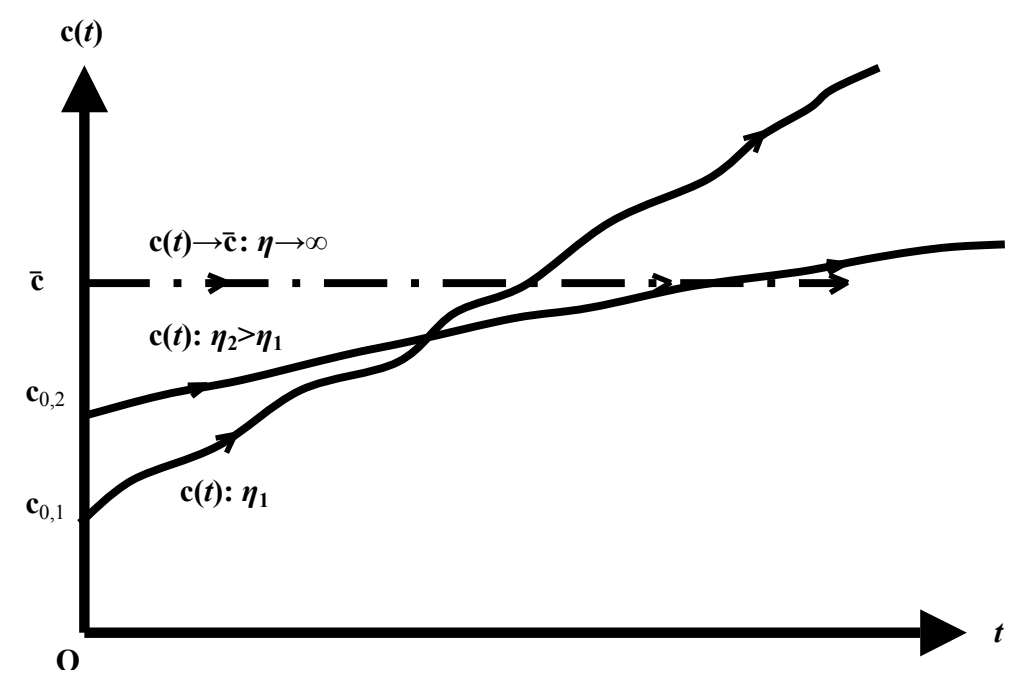

Figure 2: The Role of $\boldsymbol{\eta}$ in the utilitarian (Ramsey) model

with no discounting $(\rho=0)$

In contrast with the case of no discounting, when future welfare is discounted $(\rho>0)$, then along the utilitarian optimal path, consumption eventually declines to zero (i.e., the economy collapses in the very long-run). However, depending on the magnitude of the discount rate the path to eventual collapse differs. For very low discount rates, consumption per head first rises over time and reaches a peak and then monotonically falls over time and eventually becomes zero. This is because a very low discount rate encourages a relatively rapid capital accumulation which together with the relative resource abundance in early periods allows consumption per head to rise for some initial time interval. As Dasgupta and Heal (1979) have shown, as long as the discount rate

\footnotetext{
${ }^{4}$ Interestingly, however, the optimal policy does imply a constant savings ratio equal to $s(t)=1-c(t) / Q(t)=[1+(\eta-1) \beta] / \eta>\alpha$ (see Dasgupta and Heal (1979)). As such, the utilitarian optimal policy is intergenerationally equitable in the sense of implying equal savings burden.
} 
remains sufficiently small, a lower discount rate delays the peak of consumption per head, thus prolonging the interval during which consumption per head rises. On the other hand, for large discount rates, there will be little incentive to save and accumulate capital sufficiently to compensate for resource depletion and therefore consumption monotonically falls to zero. As such, the role of discount rate is just the opposite of that of $\eta$, so that a smaller discount rate reduces the intergenerational inequality relative to the perfectly equal distribution.

In summary, if the concept of sustainability is taken to mean a development policy that is intergenerationally just in the sense of providing equal consumption (welfare) per head to the present and all future generations, then in general the utilitarian economy falls short of being sustainable, regardless of whether future welfare is discounted or not.

\subsection{Maximin Rule of Intergenerational Justice}

The concern about intergenerational justice on the one hand and depletion of natural and environmental assets, on the other, confronts us with a basic question: If instead of adopting the utilitarian approach one were to adopt sustainability (or intergenerational equality) as the social objective, would an economy that is endowed with both manufactured capital and an essential exhaustible resource stock be able to achieve the sustainability objective in an optimal fashion?

This is exactly the question that was first tackled and elegantly answered by Solow (1974) and Hartwick (1977), leading to what is sometimes known as Solow-Hartwick sustainability rule. In its extreme form, intergenerational justice according to the Rawls' (1971) moral philosophy of choosing from the "initial position" and "behind the veil of ignorance" implies the "maximin" social welfare function. That is, the society's objective should be to maximize the well-being of the poorest generation among the present and all future generations. By implication, sustainability then requires that consumption per head to remain permanently constant over time. The optimality of the sustainable development then entails selecting the largest permanently constant consumption per capita path that is feasible, given the initial endowments of the resource stock and the manufactured capital stock. Under the assumptions of no technological change, no population growth $(n=0)$, and no depreciation of capital ( $\delta=0$ ), Solow (1974) and later on Hartwick (1977) showed that, provided that there is enough substitutability between the manufactured capital and the natural resource, it is quite possible to achieve the highest feasible level of consumption per head that remains permanently constant over time. To do so, it is sufficient that at every point in time the (scarcity) rent from the depletion of the exhaustible resource stock be invested in accumulation of the manufactured capital. This is indeed a striking and elegant theoretical result, and has some 
important implications for sustainability policy, as we shall see shortly. It is a striking result because it informs us that:

- As long as the elasticity of substitution between the natural resource and manufactured capital is at least one, even with the constraint of an exhaustible resource that is essential to production and/or to consumption, it is possible to achieve a constant consumption (utility) per head for ever. As such, one should not worry about diminishing stock of the resource, of course, as long as it is depleted optimally and is compensated for by accumulating the man-made capital optimally.

- Along the optimal path, the use of exhaustible resource declines over time, implying more use of it by early generations than by later generations. This in turn shows that sustainability (or intergenerational equality) in consumption/welfare not only does not require intergenerational equality in allocation of the resource stock itself. In fact, it may well require what ecologically may be judged an inequitable distribution of the resource stock. The same is true for the stock of manufactured capital, but, of course, in the opposite direction.

- The Solow-Hartwick rule of sustainability is an elegant theoretical result because it seems so simple: to sustain consumption per head at its highest feasible level all that is needed is to invest the rents from natural resource extraction in the reproducible capital. In other words, all that is needed for sustainability is to keep the net aggregate investment equal to zero all the time. Note that although in physical terms different generations use the natural resource (and accumulate the reproducible capital) at different rates, in harmony with equality in consumption per head, there is a sense of justice in the rule of zero-net-aggregate investment: each generation's obligation to invest in the reproducible capital is equal to the value of the natural resource stock it has drawn down. The more a generation draws on the natural resource stock the more it has to invest in the manmade capital.

It was noted above that the Rawls' maximin criterion of intergenerational justice is an extreme one. This is best appreciated by noting that the maximum sustainable level of consumption per head implied by the maximin criterion depends positively and more crucially on the initial endowment of the manufactured capital stock than on that of the natural resource stock. ${ }^{5}$ But, this means that achieving the goal of intergenerational justice according to the maximin criterion can be very costly, particularly for the poor developing nations where the initial capital stock is relatively small, for it would imply perpetuating the poverty of the present generation for all future generations. In a sense, when the initial capital stock is too small this sustainability rule implies a

\footnotetext{
${ }^{5}$ That is, the elasticity of the maximum sustainable consumption per head with respect to the initial size of man-made capital is most likely significantly larger than with respect to the initial size of resource stock (see Solow (1974) for more details).
} 
policy of "equal sharing of poverty by all generations". The undesirable consequence of pursuing a puritanical moral principle such as the maximin criterion naturally raises one's interest to contrast this outcome with the alternative possibility where tolerating some reasonable degree of intergenerational inequality- in the form of a little reduction in consumption (increased saving) by the present generation- allows to increase the welfare levels of all future generations. We shall return to this point later.

What is the relationship of the utilitarian optimal policy with the maximin sustainable policy? As noted earlier, in the case of utilitarian optimal policy, as the degree of egalitarianism of social preferences, $\eta$, increases, the optimal utilitarian path of consumption per head becomes flatter. Unsurprisingly, as $\eta$ approaches infinity the utilitarian optimal path coincides with the maximin path (see Figure 2 above) ${ }^{6}$.

\subsection{Generalization of the (Maximin) Sustainability Condition}

Before discussing the limitations and difficulties with policy application of the SolowHartwick sustainability rule, it would be helpful if we consider the rule in its most general form. Farzin (2006) has derived a necessary and sufficient condition for the sustainability of a constant consumption/utility path for a dynamically optimizing economy that is most generally characterized as follows:

- The instantaneous utility function takes the general form of $u(\mathbf{c}(t), \mathbf{s}(t), t)$, where $\mathbf{c}(t)$ is a vector of $n$ final consumption goods/services (or "bads" such as pollution flows, for example): $c_{i}(t), i=1,2, \ldots, n$, and $\mathbf{s}(t)$ is a vector of $m$ state variables, $s_{j}(t), j=1,2, \ldots, m$, representing the stocks of various types of renewable and non-renewable natural and environmental assets as well as human-made reproducible capital stocks (including human capital, knowledge capital, etc.). Possible changes in social preferences over time is also captured by the direct dependence of the utility function on time, $t$.

- The dynamics of the stocks are governed by a set of interdependent differential equations: $\dot{s}_{j}=g_{j}(\mathbf{c}(t), \mathbf{s}(t), t), \quad j=1,2, \ldots, m$. These indicate how various types of capital stocks $s_{j}(t)$ change over time, and can include the growth functions of renewable resources (human population, fisheries, forests, ground water, soil fertility, environmental quality degradation,

\footnotetext{
${ }^{6}$ Also, see Farzin (2004) for a hypothetical comparison of the optimal sustainable policies for a rich industrial county and a poor developing one using some estimates of the discount rate and $\eta$.
} 
atmospheric carbon accumulation, etc.), accumulation of reproducible capitals, depletion of exhaustible resource stocks, and possible interactions and ecological interdependencies between dynamics of various types of stocks.

Obviously, a dynamic economy characterized as above is general enough to present almost any case that one may in practice be interested to study. For example, it includes cases where the utility derives not only from consumptions of final goods and services to production of which natural and environmental resources provide inputs, but also from capital stocks themselves. Examples of the latter are the direct amenity and ecological values of environmental and natural resource stocks such as forests which are valued not only for providing timber but also for their recreational, carbon sequestering, flood controlling, water purifying, soil preservation, biodiversity preserving and other services. The system of $m$ interdependent differential equations $\dot{s}_{j}=g_{j}(\mathbf{c}(t), \mathbf{s}(t), t), \quad j=1,2, \ldots, m$ is also general enough to allow for interdependencies of various stocks on one another; for example, those of fossil fuels and carbon stocks, or of forest and biodiversity stocks, or of human population and the stocks of natural and man-made capitals. The explicit dependence on time, $t$, includes cases where in the context of a single economy or region there is an exogenous flow of population growth, technological change, or positive or negative externalities over time such as knowledge spillover or transboundry or global pollutions, and so on.

- Following Farzin (2006), one can seek the condition for an optimal sustainable utility path (when it exists) in two stages: first, by adopting the usual utilitarian approach to optimize a general utilitarian social welfare function $V=\int_{0}^{\infty} e^{-\rho t} u(\mathbf{c}(t), \mathbf{s}(t), t) d t$, and, second, obtain the condition under which this optimal path is constant over time. ${ }^{7}$ Thus, in the first stage, one can imagine that the social planner solves the following optimal control problem:

$$
\begin{aligned}
& \begin{array}{l}
\text { Maximize } \\
\{\mathbf{c}(t)\}_{0}^{\infty}
\end{array} V=\int_{0}^{\infty} e^{-\rho t} u(\mathbf{c}(t), \mathbf{s}(t), t) d t \\
& \text { subject to } \dot{s}_{j}=g_{j}(\mathbf{c}(t), \mathbf{s}(t), t), \quad j=1,2, \ldots, m \text {, } \\
& s_{j}(0)=s_{j 0} \text { (given) } \\
& \text { and the transversality conditions } \\
& \lim _{t \rightarrow \infty} \lambda_{j}(t) s_{j}(t) e^{-\rho t}=0
\end{aligned}
$$

Let $\mathbf{c}^{*}(t), \mathbf{s}^{*}(t), \lambda^{*}(t)$ be the solution to this problem, where $\lambda^{*}(t)$ is the vector of

\footnotetext{
${ }^{7}$ Note that our formulation of the solution approach to the general maximin problem in the optimal control framework is more straightforward than the unconventional and rather cumbersome optimization method adopted in Slow (1974). As such, our approach makes a methodological contribution to the literature.
} 
co-state variables (shadow prices/costs associated with capital stocks). Then the current-value Hamiltonian $H(\mathbf{c}, \mathbf{s}, \boldsymbol{\lambda}, \succsim)=u(\mathbf{c}, \mathbf{s}, \succsim)+\sum_{j=1}^{m} \lambda_{j}(\succsim) g(\mathbf{c}, \mathbf{s}, \succsim)$ is maximized along the optimal paths.

In the second stage, one can resort to Weitzman's (1976) seminal result that the maximized current-value Hamiltonian, $H(t)$, is the "stationary equivalent" of the utilitarian optimal welfare path, i.e.

$$
\int_{t}^{\infty} e^{-\rho(\tau-t)} H(t) d \tau=\int_{t}^{\infty} e^{-\rho(\tau-t)} u\left(c^{*}(\tau)\right) d \tau \quad \text { for all } t \geq 0
$$

In other words, it is the highest hypothetical constant utility path $\left.[H(\tau)\}_{t}^{\infty}=H(t)\right]$ that has the same present discounted value as the actual utilitarian (and most likely non-constant) optimal path $\left.u\left(c^{*}(\tau)\right)\right\}_{t}^{\infty}$. Using this result, Farzin (2006) has shown that:

A necessary and sufficient condition for permanently sustaining the highest constant utility/consumption path(i.e., the maximin path) is that the maximized current-value Hamiltonian remains constant over time, i.e. that $\frac{d}{d t} H(t)=0, \quad$ for all $\geq 0$.

In our problem this translates to the general condition that

$$
\frac{d H}{d t}=\frac{\partial H}{\partial t}+\rho \sum_{j=1}^{m} \lambda_{j} \dot{s}_{j}=0 \quad \text { for all } \geq 0
$$

Notice that $\frac{\partial H}{\partial t}=\frac{\partial u}{\partial t}+\sum_{j=1}^{m} \lambda_{j}(t) \frac{\partial g_{j}}{\partial t}$ measures the net change in the optimal current-value Hamiltonian at time $t$ due purely to passage of time alone. We may term this as net "pure time effect", which may be positive (for example in the case of exogenous technological progress alone, or improvements in terms of trade, or an exogenous flow of foreign aid, and so on) or negative (for example when there is exogenous population growth or the rate of decay of carbon stock in the atmosphere, or exogenous transboundry pollution flow). Accordingly, it is seen that, other things equal, a positive component of pure time effect (e.g, exogenous technological progress) makes it easier for an optimal path to be also sustainable when some of the stocks (e.g., natural and environmental assets) are depreciating or degrading. On the other hand, a negative pure time effect (e.g., exogenous growth of population over time) makes it more difficult to achieve both optimality and sustainability.

Now if for simplicity we heuristically assume away any direct and exogenous effects of time on the economy (i.e, assume the autonomous case of problem P2), so that the net "pure time 
effect" is $\frac{\partial H}{\partial t}=\frac{\partial u}{\partial t}+\sum_{j=1}^{m} \lambda_{j}(t) \frac{\partial g_{j}}{\partial t}=0$ for all $t \geq 0$, then the general maximin sustainability cum optimality condition simplifies to

$$
\frac{d H}{d t}=\sum_{j=1}^{m} \lambda_{j}(t) \dot{s}_{j}(t)=0 \quad f \text { or all } t \geq 0
$$

Interestingly, this condition is none but the generalized version of the Solow-Hartwick's sustainability rule when the Rawlsian criterion of intergenerational justice, i.e., the maximin criterion is adopted. It shows that the zero-net-aggregate-investment condition holds more generally when (1) there are many types of both natural and man-made capital stocks, (2) the well-being depends not only on a vector of final consumption goods and services but also on capital stocks, and (3) holds in the case of a time autonomous economy (where $\frac{\partial H}{\partial t}=0$ for all $\geq 0$ ) regardless of the magnitude of the positive discount rate. ${ }^{8}$ The condition requires that at every point in time the net aggregate investment be zero. To fix the idea, let us for the sake of illustration take our capital stocks to be those of a natural resource, $S_{R}(t)$, a manufactured capital, $S_{K}(t)$, a human capital, $S_{H}(t)$, a knowledge capital, $S_{N}(t)$, and a stock of pollution (say of $\left.\mathrm{CO}_{2}\right), S_{p}(t)$. If we denote the shadow price (cost in the case of pollution stock) of these stocks at time $t$, respectively by $\lambda_{R}(t), \lambda_{K}(t), \lambda_{H}(t), \lambda_{N}(t)$, and $\lambda_{p}(t)$, then the sustainability condition that

$\lambda_{R}(t) \dot{S}_{R}(t)+\lambda_{K}(t) \dot{S}_{K}(t)+\lambda_{H}(t) \dot{S}_{H}(t)+\lambda_{N}(t) \dot{S}_{N}(t)-\lambda_{p}(t) \dot{S}_{p}(t)=0, \quad$ all $t \geq 0$

is akin to a rule of optimal portfolio management: the value of changes (whether positive or negative) in any one or more stocks needs to be made up for by changes in one or more other stocks such that the net value of the changes (the net aggregate investment) is always zero. This then guarantees the maximum constant utility (or consumption in the case of one aggregated consumption good) for all the present and future generations, where the level of this maximum utility (consumption) depends on the initial endowments of all of the capital stocks, positively in

\footnotetext{
${ }^{8}$ It is important to note that while for the autonomous case of problem P2 with a constant discount rate the general sustainability of an optimal path is independent of the magnitude of the discount rate, as shown in Farzin (2006), for the same autonomous case but with a discount rate, $\rho(s)$, that declines over time the condition of zero-net-aggregate investment is still sufficient for a constant utility but it is not necessary unless the discount rate function $\rho(s)$ satisfies the condition that $\lim _{t \rightarrow \infty} \int_{0}^{t} \rho(s) d t=\infty$; that is, if the discount rate declines sufficiently slowly- a condition that is satisfied by the class of hyperbolic discount rate functions but not by the exponentially declining ones.
} 
the case of the first four stocks and negatively for the pollution stock. This is a rich theoretical insight, for it informs us that:

- The decline in one stock, for example, depletion of a natural resource, should not necessarily alarm us that the economy is on an unsustainable path, as long as it is properly compensated for by building up some other (either natural or man-made) stocks; for example by investing in human capital or in knowledge capital or in pollution abatement, or an appropriate combination of these. In particular, we note that keeping the stocks of resources intact at their current levels $\dot{S}_{R}(t)=0$, so that $S_{R}(t)=S_{R}(0)=S_{R 0}$ ), or "leaving the nature as it is" (as is sometimes advocated by some radical environmental activists in advanced industrial countries) is neither necessary nor sufficient for sustainability. In fact, although keeping all capital stocks at their current levels (so that $\dot{S}_{R}(t)=\dot{S}_{K}(t)=\dot{S}_{H}(t)=\dot{S}_{N}(t)=\dot{S}_{P}(t)=0$, all $\left.t \geq 0\right)$, or "leaving the world as it is", does trivially satisfy the sustainability condition, such a policy can lead to an inefficiently low consumption level for all generations, especially if the economy is currently poorly endowed with assets such as manufactured capital or human and knowledge capitals.

- That there are some kinds of stocks (for example, environmental and natural resource assets) the depletion of which can not be made up for by accumulation of other types of stock is, of course, an undeniable fact. But, this concern should worry us in as much as markets do not exist for their use or services or, if they exist, do not perform sufficiently well to reflect the lack of substitutability by commanding sufficiently high prices (in one form or another to reflect their use value, amenity value, intrinsic value, or precautionary/option value, etc.) to ensure that either the resource is adequately conserved or that a substitute for it is developed and introduced. In the extreme case where a minimum critical (threshold) level of a resource stock ought to be preserved in order to sustain its regenerative capacity and flow of services (or in the opposite direction, if there is a ceiling on accumulation of a pollution stock beyond which damages inflicted are irreversible) and if there is no substitute for the resource, either in consumption or production, then in principle provided that the market for the resource exists and performs well its price would rise unboundedly as the critical threshold stock level is approached, thereby ensuring that the stock will never be depleted (or accumulated, in the pollution case) to such a critical level. ${ }^{9}$ Clearly, when in reality such markets do not exist or for variety of well known reasons fail to function as expected, the

\footnotetext{
${ }^{9}$ Formally, the optimality transversality condition for a resource stock $(j)$ with a minimum threshold level ${\underset{\sim}{j}}_{j}$ (i.e., $\left.S_{j}(t) \geq \underset{\sim}{j}, \forall t \geq 0\right)$ takes the form of $\lim _{t \rightarrow \infty} \lambda_{j}(t)\left[S_{j}(t)-\underset{\sim}{S}\right] e^{-\rho t}=0$, and for a pollution stock (e.g., $\mathrm{CO}_{2}$ stock) with a ceiling constraint $\left(S_{j}(t) \leq \underset{\sim}{S_{j}}, \forall t \geq 0\right)$ the sign of the terms in the bracket will be reversed.
} 
ecologists' or ecological economists' prescription of preserving natural and environmental assets above their critical levels (also sometimes known as the "strong" sustainability criterion) ought to be heeded. ${ }^{10}$

\section{Sustainability Rule: The Practical Limitations and Challenges}

The rule of "zero-net-aggregate investment" provides some important and useful theoretical insights into sustainability of an intergenerationally equitable maximum consumption (or utility) level. However, in practice, the application of the condition faces several limitations, which in turn confront social scientists (including economists, political scientists and sociologists), natural scientists, engineers, and policymakers with serious challenges in pursuit of sustainability. Some of the most serious of these limitations and challenges are briefly discussed below:

(i) As we noted earlier, the rule requires that "capital stock" be treated in the broadest possible sense of the term. In other words, $m$ in $j=1,2, \ldots, m$, must be as comprehensive as possible. However, in practice, it is extremely difficult to identify all the existing natural as well as man-made capital assets to include knowledge capital, human capital, social capital, and other types of capitals such as institutional capital, cultural heritages, and the like. More challenging are the tasks of measuring their current stocks $\left(S_{j}(0)\right)$ and recording changes in the stocks in every period $\left(\dot{S}_{j}(t)\right)$. Although some good progress has been made in this area by developing capital accounts for some of the main renewable and non-renewable assets, the tasks of measuring human capital (including components such as skills, education level, and health status), knowledge capital (inventions and innovations), and social capital are in their infancy stage or barely undertaken in developing nations. ${ }^{11}$

(ii) Even more challenging is the task of developing a reliable knowledge of the evolution of natural and environmental capitals, their dynamic interdependences, and the production processes by which they render positive or negative flows of inputs and services essential to sustain our well being. These are probably mainly the tasks of natural scientists who should inform economists and other social scientists of the very ecological capacities and constraints that need to be taken into account as important subsets of natural and technological constraints $\left(\dot{s}_{j}=g_{j}(\mathbf{c}(t), \mathbf{s}(t), t), j=1,2, \ldots, m\right)$ in development planning.

(iii) Another difficulty in applying the sustainability rule is the task of economic evaluation of the identified stocks. As the rule requires, all of the stocks should be evaluated at their shadow prices (rents in the case of exhaustible resources). However, for many of the capital stocks, particularly

${ }^{10}$ See, for example, Daily (1977), Daly (1990), and Daly and Cobb (1991).

11 Arrow, et. al. (2004) and World Bank (2006) are among some early attempts in these regards. 
natural resources and environmental assets, either there are no markets, or if they exist, they are highly distorted by imperfect competition, imperfect information, or public policy interventions (especially subsidies on energy, water, and land). Many of natural and environmental resource and services currently lack markets, particularly in developing nations, either because of lack of recognized property rights, or deficiencies in monitoring and enforcing the rights (whether or not these rights are public, private, or communal (see Ostrom and Nagendra (2007) among many others). Even when markets exist, they are not sufficiently competitive, due to lack of free entry (as in the cases of energy, water, and land) or because of imperfect information (resulting in asymmetric information and moral hazard problems), thus entangling prices with the rents arising from both imperfections of competition and of information.

(iv) Furthermore, by definition, the shadow prices to be used for valuation of changes in capital stocks include the marginal social costs (benefits) of utilizing the stocks, As such, they diverge from market prices which fail to reflect marginal social costs (benefits) of flow and stock externalities.

(v) Externalities and Sustainability: The problem of externalities and how they relate to sustainability is an important one and goes beyond using right prices for economic valuation of changes in capital stocks. The problem of externalities gives rise to two additional and intertwined issues for application of a sustainability rule. One issue is the common misunderstanding that the use of technologies or adopting practices that mitigate negative externalities (such as environmental pollutions) is equivalent to practice of sustainability: thus, for example agriculturalists frequently refer to organic methods of production (as against conventional methods) as "sustainable agriculture". Similarly, corporations sometimes refer to the so called "green technologies"- that is, the production technologies that mitigate some form of pollution- as "sustainable industry". However, by mitigating pollution emissions, such alternative agricultural practices or manufacturing technologies reduce inefficiencies of resource allocation, and hence increase the net value of aggregate output. This is certainly desirable from efficiency point of view, but need not necessarily promote sustainability in the sense of intergenerational equality in welfare. As Bond and Farzin (2007a)(2007b) show in a simple two-sector dynamic model of an agricultural production and a consumer sector that is adversely affected by the agricultural run-offs, "agricultural sustainability", although may involve less use of fertilizers and hence less agricultural run-offs, it can well lead to more welfare inequalities both within and between generations.

(vi) Scale and Sustainability: What is the appropriate scale at which the sustainability rule should be implemented? There are two dimensions of the scale issue: one is the scale of the economic unit and the other is geographic/administrative scale. Nowadays, it is fashionable to talk about "agricultural sustainability", "corporate sustainability", "ecological sustainability", and 
sustainability at many other sectoral and sub-sectoral levels. From the perspective of a single closed economy, the sustainability rule of zero-net-aggregate investment applies at the economy wide (macroeconomic) level, and this is the right scale for policy purposes. The reason is that not only the economic sustainability rule has nothing to prescribe about sustainability at sectoral level, as its objective is the sustainability of consumption or well-being at the societal level, sustainability in one sector or the other, regardless of what sustainability definition is employed, is neither necessary nor sufficient for sustainability at the economy-wide level. In fact, insisting on sectoral sustainability, as defined for instance by sustaining profits or the rate of return on investment, or market shares or share of GDP, or well-being of people employed in one specific sector, be it agriculture, industry, or service sector, can inflict great efficiency losses on the economy as a whole and is in sharp contrast to Schumpeterian argument of "constructive destruction" 12 as a necessary condition of dynamically efficient development an economy. This is so because such sectoral constraints impede the efficient allocation of resources across the economy at any time and over time (see Bond and Farzin (2008a)(2008b)). In other words, given the interlinkages between various sectors, imposing a sustainability constraint on one sector can have adverse implications for sustainability of others.

In the more general case of an open economy, the sustainability rule presented by condition (9) should also include net changes in a country's stocks of foreign assets or debts, as the case may be. Accordingly, a country's build up of the stock of foreign debt needs to be optimally compensated for by accumulating other types of productive capital stocks, whether man-made or natural, and vice versa. This raises an interesting question about sustainability of a large exporting economy like China which over the last three decades has been experiencing a steady and high growth rate in its net trade balances, and hence the value of its net foreign assets, but at the expense of severely depleting the stocks of its natural resources, depreciating its domestic environmental assets (qualitatively and quantitatively), and contributing to the global climate change. That whether, taking into account these opposing changes, the sustainability condition (9) has been fulfilled by the Chinese economy is a purely empirical, and admittedly a daunting, question. ${ }^{13}$ Nonetheless, noting the limitations of substitution possibilities (in consumption and production) between natural and the man-made assets and the limit to accumulating foreign financial assets

\footnotetext{
${ }^{12}$ As Schumpeter (1942) noted long ago, "The fundamental impulse that sets and keeps the capitalist engine in motion comes from the new consumers, goods, the new methods of production or transportation, the new markets, the new forms of industrial organization that capitalist enterprise creates." (from Capitalism, Socialism and Democracy (New York: Harper, 1975) [orig. pub. 1942], p. 82) 
without generating risks of instability and crisis in global financial markets, it is highly doubtful if the China's current strategy of growth can be sustained for a very long period, let alone indefinitely.

(vii) What about the related issue of the geographical/adminisrtative scale at which a sustainability policy is to be implemented? In general, since there are ecological, biological, or economic, social, or political interdependencies between various ecological units (a lake, a watershed, a forest, and the like) or economic units (a village, a town, a region), limiting the implementation of a sustainability policy to a specific micro geographical or ecological or economic scale may well itself be unsustainable. This argument suggests that a sustainability policy should take as broad a view of the scale of sustainability as is relevant and feasible. At the same time, it reveals the critical role of coordination in achieving sustainability. It therefore follows that when there are strong international transboundary interdependencies (as in the cases of some fisheries, lakes, rivers, forests, and the like) or global interdependencies (such as the case of global warming, endemics, and the like), limiting the scale of sustainability to one's own national boundaries may not prove effective, at least not in the long run. By implication, this argument draws attention to the need for developing international and global sustainability institutions with the principal objectives of coordinating and facilitating the sustainability policies among various nations involved.

\section{Developing Countries: Maximin Rule of Sustainability vs. Optimal Growth}

As was noted above, the application of the policy of zero-net- aggregate investment implied by the maximin rule of intergenerational justice confronts serious difficulties. These problems are even more serious in the case of developing countries than for the rich, advanced industrial economies, thus casting doubt about suitability of a development policy based on the maximin rule of sustainability. This is because:

First, developing countries are more plagued with the problems of missing or malfunctioning markets, absent or ill-defined and ill-enforced property rights, imperfect information, and market distorting public interventions, to name a few. Also, the "pure time effects" of the factors affecting the economy exogenously and directly with time, whether positive (as in the case of disembodied technological change or knowledge spillover) or negative (as in the case of worsening of the terms of trade, or negative externalities associated with climate change), are likely to be more prevalent and pronounced in developing countries than in advanced industrial ones.

Second, more importantly, following the maximin rule of sustainability will be a particularly costly policy for developing countries. This is because, as noted above, the maximum 
consumption per head or per capita welfare level which is to be kept constant by all generations depends crucially on the currently available stocks of manufactured capital, human capital, knowledge capital, and social capital (legal and political institutions and social networks, etc.). Yet, developing counties are currently very poor in such assets, being more dependent on environmental and natural capital for their well being. Accordingly, for a poor developing country the maximin rule of sustainability would amount to all of its generations sharing and perpetuating its present poverty; that is, it will be a "poverty equalizer". This is perhaps too high a price to pay for the sake of intergenerational justice, and therefore is itself ethically questionable.

Third, as Slow (1993) has aptly pointed out, there is something of an ethical paradox with sustainability as a matter of intergenerational equity in general and with its extreme form of the maximin rule in particular. That is, if one is concerned about inequality of welfare between the present and future generations, shouldn't then one be also, at least equally, concerned about the inequality of welfare between today rich and poor, that is, about the intra-generetional equity? To be logically consistent in our moral values, we should. But then, this would call for increasing the consumption and welfare level of the currently poor by redistribution policies both within a nation and between the nations, which may in turn conflict with raising the current investment rate as required for the intergenerational welfare equality. The fact, however, is that today we tolerate a lot of poverty both at the national and international levels, which contradicts the very moral principle of seeking equality of welfare between generations; that is, the very principle of sustainability.

As is often the case, the truth lies somewhere between the two extremes: the ideal of maximin rule of intergenerational equality, on the one hand, and the heavily discounted utilitarian social welfare function, which is heavily biased towards current generation's welfare, on the other. A desirable and more practical policy seems to be the one that uses the insights from both of the two extreme approaches analyzed above. For the developing countries particularly, this translates into a compromising policy which tolerates some reasonable degree of inequality by following the utilitarian optimal path with a small discount, both intragenerationally as well as intergenerationally, for the sake of providing future generations the welfare levels that can be well above that implied by the maximin rule.

Drawing on the theoretical insights obtained from both approaches discussed above, we can outline the main and broad elements of a policy which aims to promote the growth of future welfare while at the same time mitigates the intergenerational and intragenerational welfare inequalities, thereby promoting sustainability too. These elements are:

(1) In principle, the objectives of intertemporal optimality (or dynamic efficiency) and intergenerational equality (or sustainability) need not be inconsistent as long as the efficiency gains 
can be redistributed across the present and future generations to make all generations better off than they would be if the efficiency gains were to be sacrificed in return for attaining intergenerational equality (as would be the case, for example, with the maximin rule or if one were to allocate capital stocks equally (and hence sub-optimally) across generations. The problem, however, is a lack of credible commitment devices whereby the optimality gains can actually be transferred to future generations. It is partly this lack of commitment devices that, as noted earlier, has prompted some ecologists and ecological economists to advocate what has come to be known as "strong sustainability" criterion: requiring the stocks of natural capital to be kept intact or, at least, not exploited beyond certain threshold levels. This may have some merit when, due to absence, or failure, of markets and other institutions, stocks of natural capitals are likely to be over-depleted. However, resorting to such a crude means as a substitute for a more efficient commitment device may come at the cost of inflicting significant welfare losses on all generations. The problem of lack of a commitment device for intergenerational transfer of optimality gains is likely to be particularly acute in developing countries where political and social institutions are too weak and governments are sometimes too corrupt to be trusted to act as the trustees and agents of such transfers. This point underscores the fundamental role of fighting governmental corruption and institutionalizing grass-root stakeholders' organizations as a necessary step toward democratization of political institutions, which is itself essential for sustainable and efficient economic development. Unfortunately in many developing countries natural resource rents are the monopoly of corrupt and undemocratic governments. In such cases, the welfare of both present and future generations could be better served by transferring the rights over natural assets from the government to people by distributing these assets equitably to all citizens.

(2) Even though it is virtually impossible to adopt the policy of "zero-net-aggregate-investment" at every point in time, it would still be a prudent policy to invest the rents from natural resource assets in other productive capital stocks. That is, the depreciation of natural capital stocks should be made up for by investing adequately both in natural and man-made capital stocks, and particularly in irreversible physical infrastructure, knowledge and human capital, and social capital. Unfortunately, as shown in Farzin (1999), for many of natural resource-based developing countries, the actual savings and investment rates have been far below the rates needed to ensure that the living standards of these countries would not decline over time.

(3) The policy of investing the resource rents in turn requires that all of the natural capital stocks which are used in production processes be accounted for and evaluated at correct (shadow) prices at any time point. In other words, greening of the income accounts at every level of economic activity is a fundamental step towards welfare growth and sustainability. For natural capital stocks 
particularly, this points to the vital roles of instituting and strengthening the property rights (private, communal, or public) over natural and environmental assets and enforcing these rights.

(4) A major step towards both optimality and sustainability is to internalize the externalities associated with utilization of natural and environmental resource stocks. One effective way of doing this is to price the use of these resources at their "full" marginal social costs (benefits) by levying charges and/or removing direct or indirect subsidies to avoid overexploitation of underpriced natural and environmental resources. Besides correcting for the negative externalities associated with use of natural and environmental resources, there is another important reason for making sure that natural and environmental resources are not under priced. This has to do with two factors, both of which deriving from concerns about sustainability. The first factor is the fact that resource and environmental assets in themselves have stock values in addition to their use value from harvesting or extracting them for use as inputs to production processes. Resource and environmental stock values could take the forms of amenities value, existence or intrinsic value, precautionary value, and the like. The second factor relates to the weight that a society places on the welfare of the distant future generations. In other words, it reflects the degree to which social preferences emphasize the welfare of distant future generations versus that of present generation, and ranges from the extreme of the conventional discounted utilitarian social welfare function, which completely ignores the far distant future generation, to the other extreme of the so called "green golden rule", which neglects the present by seeking the maximum ultimately sustainable utility level. In between these extremes lies the so called Chichilnisky's sustainability criterion which maximizes a social welfare function which is a weighted average of the discounted utilitarian welfare function and the green golden rule (see, Chichilnisky (1996) and Chichilnisky, Heal and Beltratti (1995)). As Heal (2000) shows, the appropriate shadow price of a natural capital will be higher the more explicitly we recognize the environmental stock as a source of value in itself and the more weight we give to the long-run future relative to the present. On both grounds, concerns about sustainability translate into raising the shadow price of environmental resources.

(5) As discussed above, today in many developing countries the living standards are very low, so that expecting the current generations to save and invest at high rates for the sake of raising future generations' welfare would be morally questionable. On the other hand, using a high constant discount rate would compromise the principle of intergenerational fairness, as it ignores the welfare of distant future generations. However, one way out of this dilemma would be to use a time-varying discount rate: specifically, a discount rate profile that starts at a relatively high rate (so as not to impose an unduly high savings burden on the current poor generation) and then declines over time as the living standards of future generations increase (so as to ensure adequate investment 
incentives to enable distant future generations to enjoy decently high living standards). Such a policy would more equitably allocate the savings burden across all generations while at the same time allows welfare to grow over time. A policy of declining discount rate is also supported by a non-ethical argument; namely, today, as an economy plans for the future, the outcomes of future technological changes and hence returns on investments become increasingly more uncertain as the planning horizon extends to more distant future, implying a declining certainty-equivalent rate of return on future investments (see, Weitzman (1999)).

(6) Finally, rather than sacrificing future generations' welfare in pursuit of a puritanical moral principle of intergenerational justice, developing counties can more pragmatically pursue an optimal growth approach to increase future welfare levels but mitigate welfare inequalities directly by redistribution of wealth and income both intragenerationally and intergenerationally. In fact, an intragenerational redistribution of income and wealth to the present poor not only need not be incompatible with the objective of sustainability cum optimality, it can even promote it provided that the redistribution take the appropriate form of enhancing the current poor's human capital. This is because by increasing the current poor's nutrition, health, and education-- factors that are essential to enabling the poor to raise their incomes and are in themselves integral components of one's overall welfare-- such a policy directly increases the poor's well-being. Furthermore, since human capital is a crucial input to productivity growth, such an intragenerational redistribution also indirectly contributes to future productivity increases.

Importantly, since sustainability considerations are meaningful when it is considered at macro scales, such redistributions of income and wealth should take place not only at the national level but internationally and globally as well. Among other policy implications, this argument has an important insight for the design of a global climate change agreement that is fair and hence likely to be acceptable to the major greenhouse gas emitters in the developing world, especially China and India. Namely, the sustainability of global climate quality requires an intragenerational redistribution of the global carbon budget (or "carbon space") from rich industrial countries to these countries. Such redistribution will be fair given that carbon emissions from the rich industrial countries in the last two centuries have been the main source of global carbon over-accumulation, thereby rendering these countries as "carbon debtors" with a moral obligation to repay their past debts to the poor "carbon lenders" such as China and India. Moreover, such (carbon wealth) redistribution (a) accords with intergenerational equity by directly reducing current generations' poverty, (b) promotes growth of future welfare, especially if the carbon debt repayments take the form of investment in human capital, and (c) helps to stabilize the global climate, especially if the repayments also include transfer of clean technologies. 


\section{Conclusion}

If we consider sustainability as a matter of intergenerational fairness, then drawing on theoretical insights received from the literature on sustainability and optimal economic growth, we can answer two basic questions: (1) Can an optimal path of development be also sustainable?, and (2) Is the maximin rule of sustainability a suitable development policy goal for the poor developing countries? We have argued that while the maximin rule of intergenerational equality may be an appropriate socio-economic goal for the rich industrial countries, for the developing countries with poor endowments of some of the critical capital assets, such as human capital, knowledge capital, and institutional capital, it is ethically questionable and practically daunting. It is ethically questionable because it subjects all future generations to the poverty of the present generation, and is impracticable because of its demand for information about existing capital stocks, their evolution over time, and the role of ecological assets in production and well-being. Finally, the requirement to have well-developed markets and non-market institutions seem unrealistic.

On the other hand, the utilitarian optimal growth approach, in its undiscounted-utility version, is capable of generating higher living standards for future generations but can result in considerable intergenerational inequality because it imposes an unacceptably high savings burden on the present generation (in its discounted-utility version, it eventually leads to an economic doomsday). For these reasons, it appears that the question should not be viewed as one of optimality versus intergenerational justice (sustainability); rather, as one of optimizing economic development while taking into account intragenerational and intergenerational fairness. Thus, we have argued that a compromise policy that combines the best features of both paradigms offers a more suitable approach to promote the rising welfare and avoid unreasonable intergenerational inequality in developing countries. We have highlighted some of the main elements of such a policy. These include: $(i)$ developing and empowering democratic political and social institutions so that the governments become accountable for reinvesting natural resources rents in reproductive capital assets (specially in human and knowledge capitals) and act as honest trustees for intergenerational transfers; (ii) instituting and strengthening the property rights over natural and environmental assets and enforcing the rights effectively; (iii) greening of the income accounts at micro and macroeconomic levels; (iv) pricing the use of natural and environmental resources at their full social opportunity costs, including the social values of their diverse services as environmental assets; ( $v$ ) using discount rates that decline over time as future generations become more prosperous; ( $v i)$ mitigating welfare inequalities directly through income and wealth redistribution policies both at the national and international levels; and (vii), adopting an economy-wide, as opposed to a sectoral, view of the scale of sustainability. 
Defined as material well-being or consumption per capita, the welfare concept underlying this analysis is narrow and limited. A more general analysis of sustainability should also recognize the importance of other components of well-being, defined more broadly to include human capital in itself and social and psychological factors (see, for example, Frey (1997) and Frey and Stutzer (2002)), and to allow for the possible trade-offs between various (material and non-material) components of social happiness. 


\section{References:}

Arrow, K. J. (1996) "What Does the Present Owe the Future?", The Grace Adams Tanner Lecture in Human Values, University of Oxford, U.K., April 11, 1996 (unpublished).

Arrow, K. J., P. Dasgupta, L. Goulder, G. Daily, P. Ehrlich, G. Heal, S. Levin, And K-G. Maler (2004) “Are We Consuming Too Much?” Economic Perspectives, Summer, Vol. 18, No. 3 , $147-172$.

Bond, C. A. and Y. H. Farzin (2008a), "Alternative Sustainability Criteria, Externalities, and Welfare in a Simple Agroecosystem Model: A Numerical Analysis", Environmental and Resource Economics, 40: 383-399.

Bond, C. A. and Y. H. Farzin (2008b), "Agroecosystem Modeling and Optimal Economic Decisions: Implications for Sustainable Agriculture", Optimal Control Applications and Methods, 29:59-80.

Chichilnisky, G. (1996), “An Axiomatic Approach to Sustainable Development”, Social Choice and Welfare, 13 (2), 219-248

Chichilnisky, G., G. M. Heal, and A. Beltratti (1995), “The Green Golden Rule”, Economic Letters, 49: 175-179.

Daly, H. E. (1990), “Toward Some Operational Principles of Sustainable Development”, Ecological Economics, 2, 1-7.

Daly, H. E. and J. B. Cobb (1991), For the common good: Redirecting the economy towards community, the environment, and a sustainable future, London: Greenprint.

Daily, G.C. (1977), ed., Nature's Services: Societal Dependence on Natural Ecosystems, Washington, DC, Island Press.

Dasgupta, P. and G. M. Heal (1979), Economic Theory and Exhaustible Resources, Cambridge.

Farzin, Y. H. (2006), "Conditions for Sustainable Optimal Economic Development", Review of Development Economics, Vol. 10, No.3: 518-534.

Farzin Y. H. (2004), "Is an Exhaustible Resource Economy Sustainable?" Review of Development Economics, Vol. 8, No.1: 33-46.

Farzin, Y. H. (1999), “Optimal Saving Policy for Exhaustible Resource Economies”, Journal of Development Economics, Vol. 58, No. 2:149-184.

Frey, B. S. (1997), Not Just for Money, Edward Elgar Publishers, Cheltenham.

Frey, B. S. and A. Stutzer (2002), "What Can Economists Learn From Happiness Research?”, Journal of Economic Literature, Vol. XL, June, 402-435. 
Hartwick, J. (1977), "Intergenerational Equity and the Investing of Rents from Exhaustible Resources, American Economic Review, 66, 792-794

Heal, G. M. (2000), "Valuing Our Future: Cost-Benefit Analysis and Sustainability", Chapter 13 in Incentives, Organization, and Public Economics: papers in Honour of Sir James Mirrlees, edited by P. J. Hammond and G.D. Myles, Oxford University Press.

Koopmans, T. C., (1967a) “Objectives, Constraints, and Outcomes in Optimal Growth Models', Econometrica, 35, 1-15.

Koopmans, T. C. (1967b) “Intertemporal Distribution and 'Optimal' Aggregate Economic Growth”, in Scientific Papers of T.C. Koopmans, M. Beckmann, C. F. Christ and M.

Nerlove (eds.), Springer Verlag, New York, 1970, 563-594.

Ostrom, E. and H. Nagendra (2007), “ Tenure Alone Is Not Sufficient: Monitoring is Essential”, Environmental Economics and Policy Studies, forthcoming.

Pezzey, J. (1989), Economic Analysis of Sustainable Growth and Sustainable Development, Environment Department working paper 15, Washington DC: World Bank.

Ramsey, F.P. (1928), “A Mathematical Theory of Saving”, Economic Journal, 38: 543-559.

Schumpeter, J. A. (1942), “Capitalism, Socialism and Democracy, New York: Harper, 1975.

Solow, R. M. (1974),'Intergenerational Equity and Exhaustible Resources", Review of Economic Studies, (Symposium), 29-4

Solow, R.M. (1993) “An Almost Practical Step Toward Sustainability”, Resources Policy 19 (3):162-172, Sept. 1993.

Stiglitz, J. E. (1974), "Growth with Exhaustible Natural Resources: Efficient and Optimal Growth Paths", Review of Economic Studies, (Symposium),

Weitzman, M.L. (1976), “On the Welfare Significance of National Product in a Dynamic Economy", Quarterly Journal of Economics, 90: 156-162

Weitzman, M.L. (1999), “Just Keep Discounting, But..”, Ch.3 in Portney, P.R. and J. P. Weyant (eds.), Discounting and Intergenerational Equity, Resources for the Future, 1999.

World Bank (1997), Expanding the Measures of Wealth: Indicators of Environmentally Sustainable Development, Washington, DC.

World Bank (2006), Where Is the Wealth of Nations?: Measuring Capital for XXI Century, Conference Edition, Washington, DC.

World Commission on Environment and Development (1987), Our Common Future (The Brundtland Report), Oxford: Oxford University Press. 
